\title{
Circulating acylghrelin levels are suppressed by insulin and increase in response to hypoglycemia in healthy adult volunteers
}

\author{
Esben S Lauritzen ${ }^{1, *}$, Thomas Voss ${ }^{1 * *}$, Ulla Kampmann ${ }^{1,2}$, Annette Mengel ${ }^{1}$, \\ Mikkel H Vendelbo ${ }^{1}$, Jens $O$ L Jørgensen ${ }^{1,2}$, Niels Møller ${ }^{1,2}$ and Esben T Vestergaard ${ }^{1}$ \\ ${ }^{1}$ Medical Research Laboratory, Aarhus University, Nørrebrogade 44, Building 3B, 8000 Aarhus C, Denmark \\ and ${ }^{2}$ Department of Endocrinology and Internal Medicine, Aarhus University Hospital, Nørrebrogade 44, \\ Building 2A, 8000 Aarhus C, Denmark \\ *(E S Lauritzen and T Voss contributed equally to this research)
}

Correspondence should be addressed to E S Lauritzen Email

esben.lauritzen@clin.au.dk

\begin{abstract}
Objective: Ghrelin has glucoregulatory and orexigenic actions, but its role in acute hypoglycemia remains uncertain. We aimed to investigate circulating levels of acylghrelin (AG) and unacylated ghrelin (UAG) in response to hyperinsulinemia and to hypoglycemia.

Design: A randomized, single-blind, placebo-controlled crossover study including 3 study days was performed at a university hospital clinical research center.

Methods: Nine healthy men completed 3 study days: i) saline control (CTR), ii) hyperinsulinemic euglycemia (HE) (bolus insulin $0.1 \mathrm{IE} / \mathrm{kg}$ i.v. and glucose $20 \%$ i.v. for $105 \mathrm{~min}$, plasma glucose $\approx 5 \mathrm{mmol} / \mathrm{l})$, and iii) hyperinsulinemic hypoglycemia $(\mathrm{HH})$ (bolus insulin $0.1 \mathrm{IE} / \mathrm{kg}$ i.v.).

Results: $\mathrm{HH}$ and HE suppressed AG concentrations at $t=45-60 \mathrm{~min}$ as compared with CTR $(P<0.05)$. At $t=90 \mathrm{~min}$, a rebound increase in $A G$ was observed in response to $H H$ as compared with both HE and CTR $(P<0.05)$. UAG also decreased during $\mathrm{HH}$ and $\mathrm{HE}$ at $t=45 \mathrm{~min}(P<0.05)$, whereas the AG-to-UAG ratio remained unaffected.

Conclusions: This study demonstrates that $A G$ and UAG are directly suppressed by hyperinsulinemia and that $A G$ concentrations increase after a latency of $\approx 1 \mathrm{~h}$ in response to hypoglycemia, suggesting a potential counterregulatory
\end{abstract} role of AG.

\section{Introduction}

Ghrelin is a 28 amino acid gut-derived peptide hormone, which is present in the circulation in an acylated (AG) and unacylated (UAG) form (1). AG is the endogenous ligand for the ghrelin receptor (2) and stimulates growth hormone (GH) and adrenocorticotropic hormone (ACTH) secretion (3). In addition, it has orexigenic effects (4). Data regarding the regulation and action of UAG are less consistent (5). The ghrelin receptor is also located in peripheral tissues, indicating direct effects of AG (6). Among these effects, glucoregulatory properties seem to be important (5) and ghrelin-deficient mice developed profound hypoglycemia during calorie restriction (7). In response to insulin-induced hypoglycemia, however, total $(8,9)$ as well as AG $(10)$ and UAG (11) levels decrease rather than increase in human subjects, irrespective of GH status (12). Whether this discrepancy reflects reciprocal effects of insulin and hypoglycemia per se remains unclear. In addition, analytical procedures may impose major limitations to clinical investigations of AG levels, because AG degrades rapidly if plasma samples are not processed appropriately (13). Furthermore, the analytical methods for measuring ghrelin concentrations have (c) 2015 The authors Published by Bioscientifica Ltd

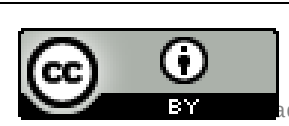

This work is licensed under a Creative Commons Attribution 3.0 Unported License. 
recently been updated (14). We therefore aimed to reassess the $A G$ and $U A G$ response to insulin-induced euglycemia and hypoglycemia using the most recent assay procedures (15).

\section{Materials and methods}

The study was conducted in accordance with the Helsinki Declaration, and all subjects gave their oral and written informed consent to participate in the trial. The local Ethics Committee approved the study protocol. The protocol was registered at Clinicaltrials.gov (ID NCT01919788). Nine healthy men averagely aged 22.5 (18-27) years with an average BMI of 23.4 (21.7-26.0) $\mathrm{kg} / \mathrm{m}^{2}$ were recruited in this study. All had a normal physical examination.

\section{Study protocol}

In a single-blind, placebo-controlled crossover study, each subject underwent 3 randomized study days, all started at $0900 \mathrm{~h}$ (time $t=0$ ): i) an i.v. bolus injection of saline (saline control, CTR); ii) an i.v. bolus injection of insulin (0.1 IE/kg; Actrapid, Novo Nordisk A/S, Bagsværd, Denmark) followed by adjustable infusion rates of glucose $20 \%$ to maintain plasma glucose as close to $5 \mathrm{mmol} / \mathrm{l}$ as possible (hyperinsulinemic euglycemia (HE)); and iii) an i.v. bolus injection of insulin (0.1 IE/ kg) (Actrapid, Novo Nordisk A/S) without glucose infusion (hyperinsulinemic hypoglycemia $(\mathrm{HH})$ ). None of the participants experienced severe symptoms during hypoglycemia. All study subjects completed all 3 study days.

On each occasion, the subjects reported to the clinical research unit at $0750 \mathrm{~h}$ after a 10-h overnight fast. The subjects were examined in a quiet, thermoneutral room. The subjects fasted during each study day. One i.v. cannula was inserted in an antecubital vein for infusion, and one i.v. cannula was inserted into a dorsal hand vein for arterializied blood sampling. Plasma glucose level was measured every $5 \mathrm{~min}$ from $t=0$ to $105 \mathrm{~min}$. Blood samples were drawn at $t=-40,0,15,30,45,60,75,90$, and $105 \mathrm{~min}$ for AG and UAG analyzes, at $t=60,75,90$, and $105 \mathrm{~min}$ for serum insulin, and at $t=60$ for serum free fatty acids (FFA) and GH.

\section{Blood samples and measurements}

Plasma glucose was analyzed by glucose oxidase method (YSI 2300 STAT plus, YSI Life Sciences, Yellow Springs, $\mathrm{OH}, \mathrm{USA})$. Serum insulin was analyzed by time-resolved fluoroimmunoassay (AutoDELFIA Insulin Kit, catalog no. B080-101; PerkinElmer, Turku, Finland). Serum FFA was analyzed by a commercial kit (Wako Chemicals, Neuss, Germany). Serum GH was analyzed by chemiluminescence technology (IDS-iSYS Multi-Discipline Automated Analyzer; Immunodiagnostic Systems Nordic, Herlev, Denmark). Plasma AG and UAG samples were drawn in $2 \mathrm{ml}$ EDTA-prepared vacutainers with $20 \mu \mathrm{l}$ of $200 \mathrm{mg} / \mathrm{ml}$ AEBSF (Sigma-Aldrich Denmark A/S) and centrifuged immediately at $2500 \mathrm{~g}$ for $10 \mathrm{~min}$ at $4{ }^{\circ} \mathrm{C}$. The plasma was then transferred to $1.8 \mathrm{ml}$ tubes and stored at $-80^{\circ} \mathrm{C}$ until analysis. AG and UAG were determined using ELISAs (Bertin Pharma, Montigny-le-Bretonneux, France; A05106 and A05119 respectively). The samples from each individual were analyzed in duplicate in one assay using a modified protocol according to Delhanty et al. (15). Plasma samples were thawed in cold water and kept on ice until transferred to the assay plates. The standards, quality controls, and samples (diluted 1:2 in assay buffer) were incubated on the plate without tracer for $2 \mathrm{~h}$ at room temperature on an orbital shaker, followed by a manual washing step (four times). The tracer antibody was added to the wells and incubated for $2 \mathrm{~h}$ at room temperature on an orbital shaker. After repeating the previous wash procedure, wells were incubated for $30 \mathrm{~min}$ in Ellmans reagent on an orbital shaker. All volumes were used as recommended in the original ELISA protocol. After the last incubation, absorbance was measured at $405 \mathrm{~nm}$ using a VICTOR $^{3} 1420$ multilabel plate reader (PerkinElmer, Waltham, MA, USA). A spline-smoothed model was used as fitting algorithm for the standard curve. The intra-assay coefficients of variation (CV) were 9.4 and $9.5 \%$ and the inter-assay CV were 10.9 and $14.3 \%$ for the AG and UAG kits respectively.

\section{Statistical analyses}

Results are expressed as means \pm s.E.M, mean and range Homeostatic Model Assessment of Insulin Resistance (HOMA-IR), and median and range (serum insulin). One subject was excluded from the statistical analyses because AG and UAG levels were increased from 50- to 100 -fold as compared with the mean concentrations in the remaining subjects. The statistical analysis is therefore based on eight data sets. The statistical analyses were performed by using SigmaPlot 11.0 (Systat Software, Inc., San Jose, CA, USA). A two way-ANOVA (time $\times$ treatment) for repeated measurements with StudentNewman-Keuls post hoc analysis was used to test for significant differences in the major endpoints of this 
study. A Pearson's Product Moment was used for correlation analysis. Baseline concentrations of AG, UAG, and plasma glucose were analyzed using one-way ANOVA for repeated measures. GH and FFA concentrations were also analyzed using a one-way ANOVA for repeated measures with Student-Newman-Keuls post hoc analysis. Insulin concentrations were analyzed using a one-way ANOVA for ranks for repeated measures. A $P<0.05$ was considered to be statistically significant.

\section{Results}

\section{Plasma glucose}

Baseline concentrations of plasma glucose were similar $(\mathrm{mmol} / \mathrm{l})(5.0 \pm 0.1$ (CTR) vs $5.0 \pm 0.1$ (HE) vs $5.0 \pm 0.1$ $(\mathrm{HH}), P=0.78)$ (Fig. 1A). Plasma glucose was unchanged at $t=30 \mathrm{~min}$ on the CTR day $(4.9 \pm 0.1)$, whereas it increased on the HE day $(5.5 \pm 0.1, P=0.01)$ and reached nadir on the $\mathrm{HH}$ day $(2.3 \pm 0.2, P<0.001)$. Plasma glucose was slightly increased from $t=30 \mathrm{~min}$ during $\mathrm{HE}$ as compared with CTR.

\section{Insulin}

Overall, a pooled mean of serum insulin concentrations from $t=60$ to 105 differed between CTR, HE, and $\mathrm{HH}$, ANOVA-P $<0.001$. On the CTR day (42 (29-58) pmol/l) and $\mathrm{HH}$ day (34 (23-81) pmol/1), serum insulin was similar, but serum insulin increased in response to HE (78 (59-129) pmol/l) as compared with $\mathrm{HH}, P<0.05$ and CTR, $P<0.05$.

\section{Free fatty acid}

At $t=60 \mathrm{~min}$, serum FFA differed between CTR, HE, and $\mathrm{HH}, \mathrm{ANOVA}-\mathrm{P}<0.001$, and pairwise comparisons also revealed differences between the three interventions $(\mathrm{mmol} / \mathrm{l})(0.57 \pm 0.07$ (CTR) vs $0.09 \pm 0.02(\mathrm{HE})$, $P<0.001 ; 0.09 \pm 0.02$ (HE) vs $0.27 \pm 0.05(\mathrm{HH}), P=0.028$; and $0.57 \pm 0.07$ (CTR) vs $0.27 \pm 0.05(\mathrm{HH}), P=0.002)$.

\section{Growth hormone}

At $t=60$ min, serum $\mathrm{GH}$ differed between CTR, $\mathrm{HE}$, and $\mathrm{HH}$, ANOVA-P $<0.001$. A post hoc analysis showed no difference between CTR and HE ( $\mu \mathrm{g} / \mathrm{l})(1.9 \pm 0.7$ (CTR) vs $0.9 \pm 0.3$ (HE), $P=0.465)$, but comparisons between the other interventions showed an increase in GH in response to hypoglycemia $(17.8 \pm 1.7(\mathrm{HH})$ vs $0.9 \pm 0.3(\mathrm{HE}), P<0.001$ and $1.9 \pm 0.7(\mathrm{CTR})$ vs $17.8 \pm 1.7(\mathrm{HH}), P<0.001)$.

\section{Acylated ghrelin}

Baseline concentrations of plasma AG were comparable $(\mathrm{pg} / \mathrm{ml})(64.0 \pm 21.3$ (CTR) vs $57.9 \pm 16.7$ (HE) vs $63.8 \pm$ 19.2 (HH), $P=0.79$ ) (Fig. 1B). Overall, plasma AG levels

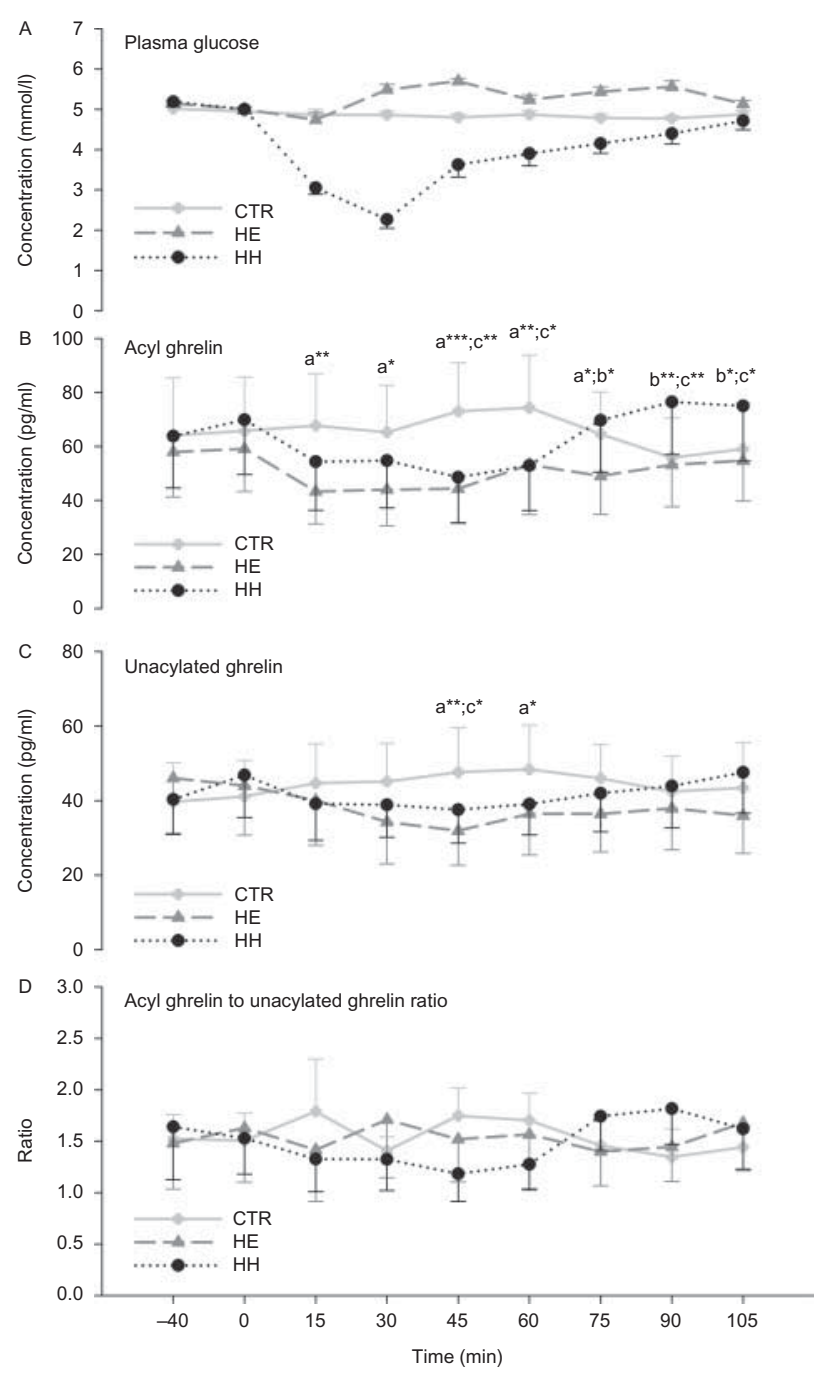

\section{Figure 1}

Healthy males underwent three interventions: i) saline control (CTR), ii) an insulin bolus injection followed by glucose infusion $(\mathrm{HE})$, and iii) an insulin bolus injection (hyperinsulinemic hypoglycemic ( $\mathrm{HH}$ ) conditions). (A) Plasma glucose concentrations during the three conditions. (B) Plasma acylghrelin concentrations $(\mathrm{pg} / \mathrm{ml})$ in response to the three interventions. (C) Plasma unacylated ghrelin concentrations $(\mathrm{pg} / \mathrm{ml})$ in response to the three interventions. (D) Acyl ghrelin-to-unacylated ghrelin ratio in response to the three interventions. Comparisons: $\mathrm{a}=\mathrm{HE}$ vs $\mathrm{CTR} ; \mathrm{b}=\mathrm{HE}$ vs $\mathrm{HH}$; and $\mathrm{c}=\mathrm{HH}$ vs CTR. Statistical significance: ${ }^{*} P<0.05 ; * * P<0.01$; and $* * * P<0.001$. Statistically significant differences in glucose concentrations are not shown. 
were significantly different between CTR, HE, and $\mathrm{HH}$ (time $\times$ treatment interaction, $P<0.001$ ). Post hoc analyses revealed that plasma AG concentrations were decreased from $t=15$ to 75 min during HE as compared with CTR, $P<0.05$ and from $t=75$ to $105 \mathrm{~min}$ during HE as compared with $\mathrm{HH}, P<0.05$. Plasma AG concentrations also decreased significantly from $t=45$ to $60 \mathrm{~min}$ during $\mathrm{HH}$ as compared with CTR, $P<0.05$. However, during $\mathrm{HH}$, plasma AG concentrations showed $\mathrm{a} \approx 37 \%$ rebound increase at $t=90 \min (P=0.008)$ as compared with CTR, which remained significant at $t=105 \mathrm{~min}(P=0.04)$.

\section{Unacylated ghrelin}

Baseline concentrations of plasma UAG were comparable on each occasion $(\mathrm{pg} / \mathrm{ml})(39.7 \pm 10.5$ (CTR) vs $46.0 \pm 14.8$ (HE) vs $40.3 \pm 9.3(\mathrm{HH}), P=0.45$ ) (Fig. 1C). Overall, plasma UAG levels changed significantly with time and treatment (time $\times$ treatment interaction, $P=0.004$ ). Post hoc analyses revealed that plasma UAG concentrations were decreased from $t=45$ to 60 min during HE as compared with CTR, $P=0.001$ and 0.04 , respectively, and plasma UAG concentrations were significantly decreased at $t=45 \mathrm{~min}$ during $\mathrm{HH}$ as compared with CTR, $P=0.04$. However, no rebound increase in plasma UAG levels was recorded in response to hypoglycemia.

\section{AG-to-UAG ratio}

Overall, the AG-to-UAG ratios were significantly different between CTR, HE, and $\mathrm{HH}$ (time $\times$ treatment interaction, $P=0.01$ ), but post hoc analyses revealed no differences between the interventions at different time points.

\section{Insulin sensitivity and correlations with AG and UAG}

The HOMA-IR was 0.81 (range 0.53-1.10). There was an inverse correlation between HOMA-IR and the decline in AG during HE conditions, $R=-0.8, P=0.017$, but no significant correlation with the decline in UAG, $R=-0.69, P=0.056$. No correlation was recorded during $\mathrm{HH}$ with regards to the decline in AG, $R=-0.32, P=0.45$ or in UAG, $R=-0.53, P=0.18$.

\section{Discussion}

The aim of this study was to investigate whether AG increases in response to acute insulin-induced hypoglycemia. The metabolic response to hypoglycemia involves the release of counterregulatory hormones including
ACTH and GH, which mobilize fatty acids and suppresses glucose uptake. In addition, hypoglycemia also stimulates appetite (16). Insulin, on the other hand, primarily promotes anabolism and glucose uptake. Taken together, it would be teleologically meaningful if AG levels are suppressed by insulin and stimulated by hypoglycemia. This study demonstrates that AG and UAG measured by updated assays are initially suppressed by hyperinsulinemia, which is in concordance with studies using older assays $(8,9,10,11)$. Our study demonstrates an independent effect of acute hyperinsulinemia on both AG and UAG levels in the absence of a change in plasma glucose levels. In concordance with a previous report (8), we revealed a significant correlation between the decline of AG during hyperinsulinemia and euglycemia and insulin sensitivity. Reciprocal effects of hypoglycemia and hyperinsulinemia on AG secretion may explain the lack of correlation during hyperinsulinemia and hypoglycemia. The molecular mechanisms regulating ghrelin secretion have been investigated in an in vitro study in newborn rat stomach cells (17). In that study, insulin incubation directly inhibited ghrelin secretion through an increase in phosphorylated serine-threonine kinase (AKT) and a reduction in intracellular cAMP. Patients suffering from anorexia nervosa are characterized by low systemic insulin levels and hypoglycemia in concomitance with elevated ghrelin levels $(18,19)$, which are in accordance with our experimental data.

We observed a rebound increase in AG $\sim 1 \mathrm{~h}$ after the insulin injection, and it persisted for the rest of the study day. Blood was sampled until $105 \mathrm{~min}$ after the insulin injection and it is uncertain how long time the $A G$ increase lasts after hyperinsulinemia and hypoglycemia. The early-rebound increase in AG as compared with the more stable UAG levels following hyperinsulinemia suggests an acute effect on the regulation of AG-to-UAG ratio. This effect could hypothetically be attributable to acylation rate of newly synthesized ghrelin or reduced disposal, but the mechanism remains to be determined. A rebound increase in AG could contribute to the increased hunger after an episode of hypoglycemia. The rebound increase in AG levels after hypoglycemia has not been reported in earlier studies on AG concentrations during hypoglycemia, which may be due to a combination of lack of a placebo control day and an euglycemic day (10) and analytical imprecision. It is unlikely that the rebound increase in AG following hyperinsulinemia and hypoglycemia is caused by increased concentrations of GH or FFA, because previous reports showed that total ghrelin was not correlated with GH (20) and that increased concentrations 
of FFA reduce total concentrations of ghrelin (21). In our study, we report AG-to-UAG ratios close to $150 \%$, which is significantly higher than previous estimates ranging from $4 \%$ (1) to $50 \%$ (22). We believe that our data yield a better estimate due to improved sample handling and assay technique.

There are some limitations to our study. We aimed to clamp plasma glucose at $5 \mathrm{mmol} / \mathrm{l}$, equal to the plasma glucose levels on the CTR day, in order to unravel the isolated effects of hyperinsulinemia on systemic ghrelin concentrations. However, plasma glucose levels increased on the study day with concomitant insulin injection and glucose infusion as compared with the CTR day, which resulted in slightly increased insulin levels during the terminal period of the HE study day. Glucose infusion has been shown to suppress ghrelin levels (23), and this in addition to increased concentrations of insulin could explain why AG and UAG concentrations were slightly lower on the intervention with insulin and glucose.

In conclusion, this study demonstrates that AG and UAG are directly suppressed by hyperinsulinemia and that AG concentrations increase after a latency of $\approx 1 \mathrm{~h}$ in response to hypoglycemia, suggesting a potential counterregulatory role of AG. Whether hypoglycemia-induced appetite stimulation is related to increased AG concentrations should be addressed in future studies.

\section{Declaration of interest}

The authors declare that there is no conflict of interest that could be perceived as prejudicing the impartiality of the research reported.

\section{Funding}

The study received support from the Danish Council for Strategic Research ('Keto-group' - \#0603-00479B). The study was also supported by a postdoctoral research fellow grant (11-105283) and a pregraduate scholarship (4004-00007B) from the Danish Council for Independent Research (Medical Sciences). Finally, we received a grant from Aase and Ejnar Danielsens Foundation (10-001172).

\section{Acknowledgements}

The authors thank Mrs K N Rasmussen and Mrs E Hornemann for excellent technical assistance.

\section{References}

1 Hosoda H, Kojima M, Matsuo H \& Kangawa K. Ghrelin and des-acyl ghrelin: two major forms of rat ghrelin peptide in gastrointestinal tissue. Biochemical and Biophysical Research Communications 2000279 909-913. (doi:10.1006/bbrc.2000.4039)
2 Kojima M, Hosoda H, Date Y, Nakazato M, Matsuo H \& Kangawa K. Ghrelin is a growth-hormone-releasing acylated peptide from stomach. Nature 1999402 656-660. (doi:10.1038/45230)

3 Takaya K, Ariyasu H, Kanamoto N, Iwakura H, Yoshimoto A, Harada M, Mori K, Komatsu Y, Usui T, Shimatsu A et al. Ghrelin strongly stimulates growth hormone release in humans. Journal of Clinical Endocrinology and Metabolism 200085 4908-4911. (doi:10.1210/jcem.85.12.7167)

4 Wren AM, Seal LJ, Cohen MA, Brynes AE, Frost GS, Murphy KG, Dhillo WS, Ghatei MA \& Bloom SR. Ghrelin enhances appetite and increases food intake in humans. Journal of Clinical Endocrinology and Metabolism 200186 5992. (doi:10.1210/jcem.86.12.8111)

5 Heppner KM \& Tong J. Mechanisms in endocrinology: Regulation of glucose metabolism by the ghrelin system: multiple players and multiple actions. European Journal of Endocrinology 2014171 R21-R32. (doi:10.1530/EJE-14-0183)

6 Papotti M, Ghe C, Cassoni P, Catapano F, Deghenghi R, Ghigo E \& Muccioli G. Growth hormone secretagogue binding sites in peripheral human tissues. Journal of Clinical Endocrinology and Metabolism $2000 \mathbf{8 5}$ 3803-3807. (doi:10.1210/jcem.85.10.6846)

7 Zhao TJ, Liang G, Li RL, Xie X, Sleeman MW, Murphy AJ, Valenzuela DM, Yancopoulos GD, Goldstein JL \& Brown MS. Ghrelin $O$-acyltransferase (GOAT) is essential for growth hormone-mediated survival of calorie-restricted mice. PNAS 2010107 7467-7472. (doi:10.1073/pnas.1002271107)

8 Lucidi P, Murdolo G, Di Loreto C, De Cicco A, Parlanti N, Fanelli C, Santeusanio F, Bolli GB \& De Feo P. Ghrelin is not necessary for adequate hormonal counterregulation of insulin-induced hypoglycemia. Diabetes 200251 2911-2914. (doi:10.2337/diabetes.51.10.2911)

9 Flanagan DE, Evans ML, Monsod TP, Rife F, Heptulla RA, Tamborlane WV \& Sherwin RS. The influence of insulin on circulating ghrelin. American Journal of Physiology. Endocrinology and Metabolism 2003284 E313-E316. (doi:10.1152/ajpendo.00569.2001)

10 Kim SW, Kim KW, Shin CS, Park do J, Park KS, Cho BY, Lee HK \& Kim SY. Acylated ghrelin secretion is acutely suppressed by oral glucose load or insulin-induced hypoglycemia independently of basal growth hormone secretion in humans. Hormone Research 200767 211-219. (doi:10.1159/000097098)

11 Blijdorp K, van der Lely AJ, van den Heuvel-Eibrink MM, Huisman TM, Themmen AP, Delhanty PJ \& Neggers SJ. Desacyl ghrelin is influenced by changes in insulin concentration during an insulin tolerance test. Growth Hormone \& IGF Research 201323 193-195. (doi:10.1016/j.ghir.2013.06.003)

12 Ryber L, Obrink K, Houe N, Frystyk J \& Jorgensen JO. Serum ghrelin levels are suppressed in hypopituitary patients following insulininduced hypoglycaemia irrespective of GH status. Clinical Endocrinology 200665 210-214. (doi:10.1111/j.1365-2265.2006.02575.x)

13 Hosoda H, Doi K, Nagaya N, Okumura H, Nakagawa E, Enomoto M, Ono F \& Kangawa K. Optimum collection and storage conditions for ghrelin measurements: octanoyl modification of ghrelin is rapidly hydrolyzed to desacyl ghrelin in blood samples. Clinical Chemistry 2004 50 1077-1080. (doi:10.1373/clinchem.2003.025841)

14 Blatnik M, Soderstrom CI, Dysinger M \& Fraser SA. Prandial ghrelin attenuation provides evidence that des-acyl ghrelin may be an artifact of sample handling in human plasma. Bioanalysis 20124 2447-2455. (doi:10.4155/bio.12.248)

15 Delhanty PJ, Huisman M, Julien M, Mouchain K, Brune P, Themmen A, Abribat T \& van der Lely A. The acylated (AG) to unacylated (UAG) ghrelin ratio in esterase inhibitor treated blood is higher than previously described. Clinical Endocrinology 201582 142-146. (doi:10.1111/cen.12489)

16 Schultes B, Oltmanns KM, Kern W, Fehm HL, Born J \& Peters A. Modulation of hunger by plasma glucose and metformin. Journal of Clinical Endocrinology and Metabolism 200388 1133-1141. (doi:10.1210/ jc.2002-021450)

17 Gagnon J \& Anini Y. Insulin and norepinephrine regulate ghrelin secretion from a rat primary stomach cell culture. Endocrinology 2012 153 3646-3656. (doi:10.1210/en.2012-1040) 
18 Winston AP. The clinical biochemistry of anorexia nervosa. Annals of Clinical Biochemistry 201249 132-143. (doi:10.1258/acb.2011.011185)

19 Ariyasu H, Takaya K, Tagami T, Ogawa Y, Hosoda K, Akamizu T, Suda M, Koh T, Natsui K, Toyooka S et al. Stomach is a major source of circulating ghrelin, and feeding state determines plasma ghrelin-like immunoreactivity levels in humans. Journal of Clinical Endocrinology and Metabolism 200186 4753-4758. (doi:10.1210/jcem.86.10.7885)

20 Gormsen LC, Nielsen C, Gjedsted J, Gjedde S, Vestergaard ET, Christiansen JS, Jorgensen JO \& Moller N. Effects of free fatty acids, growth hormone and growth hormone receptor blockade on serum ghrelin levels in humans. Clinical Endocrinology 200766 641-645. (doi:10.1111/j.1365-2265.2007.02786.x)
21 Gormsen LC, Gjedsted J, Gjedde S, Vestergaard ET, Christiansen JS, Jorgensen JO, Nielsen S \& Moller N. Free fatty acids decrease circulating ghrelin concentrations in humans. European Journal of Endocrinology 2006154 667-673. (doi:10.1530/eje.1.02146)

22 Tong J, Dave N, Mugundu GM, Davis HW, Gaylinn BD, Thorner MO, Tschop MH, D'Alessio D \& Desai PB. The pharmacokinetics of acyl, des-acyl, and total ghrelin in healthy human subjects. European Journal of Endocrinology 2013168 821-828. (doi:10.1530/EJE-13-0072)

23 Broglio F, Gottero C, Prodam F, Destefanis S, Gauna C, Me E, Riganti F, Vivenza D, Rapa A, Martina V et al. Ghrelin secretion is inhibited by glucose load and insulin-induced hypoglycaemia but unaffected by glucagon and arginine in humans. Clinical Endocrinology 200461 503-509. (doi:10.1111/j.1365-2265.2004.02121.x)

Received 16 October 2014

Revised version received 4 December 2014

Accepted 15 January 2015 